\title{
Sobre a atualidade do conceito de imperialismo nas relações interestatais
}

On the topicality of the concept of imperialism concerning the relations among states

\section{Marcelo pereila Fernandes*}

DOI: https://doi.org/10.4322/principios.2675-6609.2021.161.004

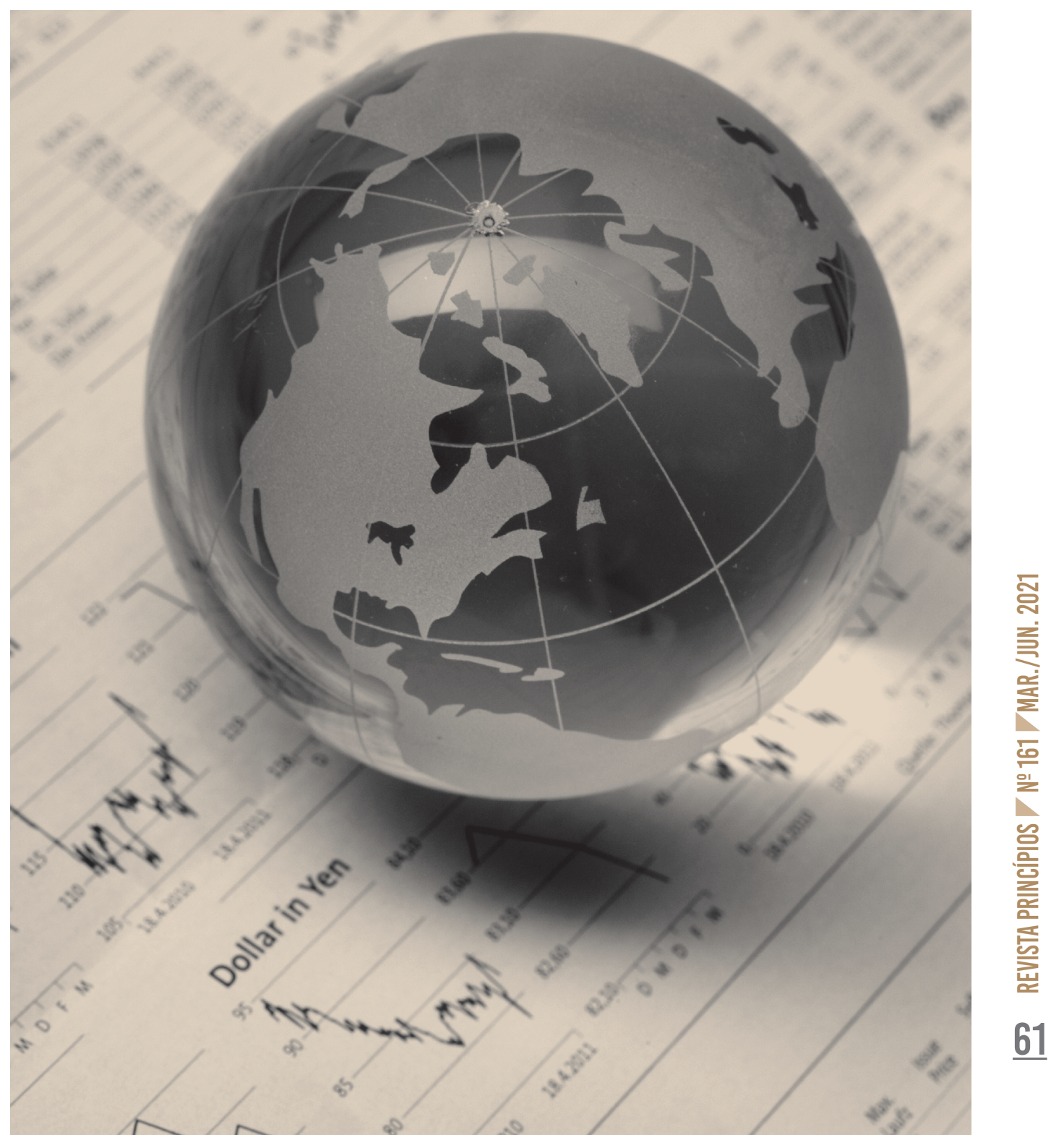




\section{RESUMO}

O fim dos anos 1980 marca um momento importante quanto à expansão do capital. Com isso, diversos autores e organismos internacionais adotaram o termo globalização para explicar as transformações mundiais ocorridas nas últimas décadas do século XX. Tais transformações teriam como pano de fundo o enfraquecimento do poder do Estado-nação. Certos autores de influência marxista trilharam esse caminho, argumentando que a globalização (neoliberal) marcaria uma transição para uma nova fase histórica. Alguns alegam que a globalização teria superado o imperialismo, ou que a globalização seria uma nova forma de imperialismo, enquanto outros passaram a usar esses dois conceitos quase indistintamente. O objetivo deste artigo é demonstrar a atualidade do conceito de imperialismo para descrever as relações interestatais. O termo globalização descreve um mundo capitalista sem fronteiras, unificado e acessível para um capital supostamente apátrida, obscurecendo ou mesmo negando aspectos fundamentais a respeito do funcionamento do sistema internacional. Portanto, suprime a possibilidade de detectar uma série de problemas relacionados ao desenvolvimento histórico das relações de exploração no capitalismo e ao papel do imperialismo como referência teórica e histórica.

Palavras-chave: Imperialismo. Globalização. Cadeia imperialista. Relações interestatais.

\section{ABSTRACT}

The late I980s marked an important moment in terms of capital expansion. Thus, several authors and international organizations adopted the term globalization to explain the world transformations that occurred in the last decades of the 20 th century. Such transformations would have as a backdrop the weakening of the power of nation-state. Certain authors of Marxist influence followed this path, arguing (neoliberal) globalization would mark a transition to a new historical phase. Some claim that globalization would have overcome imperialism, or that globalization would be a new form of imperialism, while others began to use these two concepts almost indistinctly. The aim of this article is to demonstrate the current explanatory power of the concept of imperialism to describe relations among States. The term globalization describes a capitalist world without borders, unified and accessible to a supposedly stateless capital, obscuring or even denying fundamental aspects regarding the functioning of the international system. Therefore, it suppresses the possibility of detecting a series of problems related to the historical development of exploitative relations in capitalism and to the role of imperialism as a theoretical and historical reference.

Keywords: Imperialism. Globalization. Imperialist chain. Relations among States. 


\section{INTRODUÇ̃̃o}

O fim dos anos I980 marca um momento importante quanto à expansão do capital. Com isso, diversos autores e organismos internacionais adotaram o termo globalização para explicar as transformações mundiais ocorridas nas últimas três décadas do século XX. Tais transformações evocariam uma nova ordem mundial que teria como pano de fundo a decadência do Estado-nação. A "globalização" passou a ser pretexto para quase tudo que ocorre (RUCCIO, 2003). Desde o aumento do desemprego e a degradação cultural em países periféricos até o avanço tecnológico e da democracia ocidental, teríamos assim um único fator responsável: a globalização. É um conceito pouco preciso, porém com muita força política no sistema de ideias dominantes (MORAES, I996): para alcançar os benefícios prometidos, e impedir possíveis danos, governos deveriam se comprometer com políticas neoliberais como abertura comercial e financeira, reformas no mercado de trabalho, privatização de empresas, política monetária rígida, equilíbrio fiscal etc.

Sem endossar tais políticas, alguns autores de influência marxista trilharam caminho semelhante, argumentando que a globalização marcaria uma transição para uma nova fase histórica em que o capital não precisaria mais do Estado. Alguns argumentam que a globalização teria superado o imperialismo, enquanto outros passaram a usar os dois conceitos quase que indistintamente ou ainda que a globalização seria uma nova forma de imperialismo ou neoimperialismo (RUCCIO, 2005).

Há um traço semelhante entre as interpretações daqueles que consideram que o imperialismo não seria mais um conceito válido: o mundo não estaria mais dividido em países exploradores e países explorados, uma vez que as colônias praticamente já não existem e os Estados não possuiriam mais tanta importância no processo de acumulação. O capitalismo teria unificado o mundo nos tempos da globalização e não teríamos os impérios formais, como existiam no começo do século XX.

Grande parte da literatura que trata do fenômeno do imperialismo buscou conceituá-lo como uma forma de exploração dos países pobres pelos países ricos, que bloquearia o desenvolvimento dos primeiros. Esse conceito, amplamente difundido, tem sido usado sobretudo para denunciar o imperialismo "ruim" como o culpado por toda a miséria que aflige o mundo, deixando a análise superficial, como advertem Milios e Sotiropoulos (2009).

Entre os principais proponentes desse conceito de imperialismo está Rosa Luxemburgo, com sua obra A acumulação de capital: estudo sobre a interpretação econômica do imperialismo. O imperialismo seria interpretado como uma luta entre as economias capitalistas desenvolvidas pela dominação dos territórios não capitalistas em razão de uma crise de realização permanente no mercado capitalista. Em outras palavras, o imperialismo se referiria ao processo de colonização pelas potências capitalistas.

Por sua vez, Baran e Sweezy (1978) levantaram a tese de que os investimentos externos das multinacionais dos países centrais teriam a função de sugar o exce- 
dente econômico dos países subdesenvolvidos. Na dinâmica do capitalismo monopolista dominado por empresas gigantes, o excedente econômico como proporção do produto nacional tenderia a se elevar. Isso significa que a proporção da renda disponível ao consumo dos trabalhadores seria cada vez menor, o que levaria a economia à estagnação. Aqui entrariam os gastos estatais crescentes, cumprindo um importante papel nas economias centrais. Em particular, os extraordinários dispêndios do Estado vinculados ao militarismo teriam duas funções. Primeiramente, absorveriam parte do excedente econômico crescente, impedindo a estagnação econômica. E em segundo lugar, manteriam o mundo seguro para as operações das multinacionais.

A análise de Baran e Sweezy (1978) teve influência considerável nas chamadas teorias da dependência que foram desenvolvidas principalmente com base em uma visão que elegia a América Latina como objeto principal. Autores como Santos (1973), Wallerstein (1979) e Marini (1977; 1980), entre outros, comungavam da mesma conclusão acerca do imperialismo: a impossibilidade de desenvolvimento na periferia do capitalismo nos marcos da estrutura vigente no sistema internacional.

Desse modo, no fim do século XX o conceito de imperialismo, visto por esse prisma, foi considerado ultrapassado, e mesmo autores da tradição marxista passaram a questionar sua relevância. Robinson $(2007$, p. 5$)$ representa bem essa visão:

As relações de classe do capitalismo global estão agora tão profundamente internalizadas em cada Estado-nação que a imagem clássica do imperialismo como uma relação de dominação externa está desatualizada. O fim da extensa expansão do capitalismo é o fim da era imperialista do capitalismo mundial (tradução nossa).

Com efeito, não apenas o conceito de globalização parecia ter substituído o de imperialismo, mas até mesmo a própria existência de um modo de produção capitalista passou a ser negligenciada. Pelo menos até o começo dos anos 2000, a palavra imperialismo ficou relegada ao segundo plano das pesquisas. Além disso, questões como degradação do meio ambiente, migração, povos indígenas e desigualdade de renda, gênero e desenvolvimento, que antes eram apresentadas no âmbito da discussão sobre imperialismo, passaram a ser tratadas como temas separados ou até autônomos, empobrecendo o debate (HALLIDAY, 2002).

Em contraposição a essas leituras, na análise de Lênin (1979; s.d.), à medida que o capitalismo se desenvolve, a dinâmica internacional é determinada essencialmente pelos conflitos entre as potências capitalistas. Ainda que a relação entre as economias centrais e periféricas tenha importância, não é o cerne da crítica. Conforme pretendemos demonstrar, em contraste com a ideia de globalização, a concepção de imperialismo apresentada por Lênin ainda é uma descrição válida das relações hierárquicas, desiguais e complexas advindas da reprodução do capital no sistema internacional. Em vista disso, ela contribui para esclarecer a atual conjuntura internacional de instabilidade política e econômica originada da crise financeira de 2008 , 
em que o fracasso das grandes potências em criar alguma nova forma de "governança econômica mundial" é um dos seus aspectos mais reveladores.

De fato, existe um aumento da internacionalização da economia, com maior liberdade ao movimento de capitais quando comparado ao período pós-guerra. Por sua vez, o mundo está cada vez mais parecido com aquele do início do século XX, não apenas em relação ao crescimento dos fluxos de capitais, mas também quanto ao crescimento da desigualdade de renda e riqueza e da competição em todo o mundo. Ademais, conforme Tarso (I996, p. I48) alertava, "a ênfase na globalização, sua enorme divulgação e popularidade, explica-se, também, pela necessidade política de negar validade teórica a textos escritos, no começo do século, por expoentes marxistas".

O objetivo deste artigo é analisar a atualidade do imperialismo nas relações interestatais. A ideia de globalização (neoliberal) descreve um mundo capitalista com Estados fracos, sem fronteiras, unificado e sustentado por grandes empresas transnacionais, em que as dinâmicas sociais são consequência dessa nova ordem. Embora seja um termo consagrado, geralmente expressando uma nova fase do capitalismo, entendemos que ele dificulta a assimilação de aspectos cruciais quanto ao funcionamento do sistema internacional, suprimindo uma série de problemas relacionados ao desenvolvimento histórico das relações de exploração no sistema capitalista e ao papel do imperialismo como referência teórica e histórica.

Além desta introdução, o artigo está dividido em mais três seções. Na seção seguinte discutiremos o conceito de globalização e as contribuições de autores marxistas em relação à noção de enfraquecimento dos Estados-nação. Na terceira seção faremos uma crítica à globalização por meio do conceito de imperialismo, tendo como base principalmente autores da tradição leninista. Por fim, breves considerações finais encerram o artigo.

\section{A "GlOBALIZAĈ̣̃O"}

De acordo com o pensamento neoliberal, a globalização é um processo inevitável que estaria modificando os princípios estabelecidos nas últimas décadas sobre a economia, a cultura e a soberania dos Estados nacionais. Em um sentido otimista, esses princípios estariam se dissolvendo em função de um sistema econômico global livre das barreiras aos fluxos de capitais, mercadorias e serviços; isto é, a economia mundial teria encontrado seu "estado natural"' (MARQUES, I996).

Assim, a globalização seria o resultado de um longo processo, no qual o avanço tecnológico e das comunicações exerceu um papel vital na alocação mais eficiente dos recursos produtivos por meio da competição e da divisão internacional do trabalho. As grandes empresas teriam passado a dominar os mercados mundiais. Isso, por sua vez, provocaria o forte declínio da importância do Estado-nação e, ao mesmo tempo, uma melhora generalizada dos padrões de vida em todo o mundo (SCOTT,

1 A livre movimentação da força de trabalho nunca esteve entre as prioridades. Mas esse "detalhe" não é muito lembrado. 
200I; DI GIOVANNI et al., 2008). Um modelo a ser seguido por todos os países que desejem usufruir dos benefícios da integração da economia mundial ${ }^{2}$.

Ainda segundo a perspectiva neoliberal, a globalização favoreceria não apenas o crescimento econômico, mas também outros objetivos não ligados diretamente à economia (FRANKEL, 2000). Entre esses objetivos estaria a ampliação dos regimes democráticos liberais numa "nova ordem mundial”, conforme anunciou George Bush em I99I. Essa percepção foi representada por Francis Fukuyama. Segundo ele, o poder da economia de mercado advém da superioridade da democracia liberal ocidental sobre outras formas de governo, como se as instituições do Ocidente tivessem alcançado um nível de perfeição inigualável (FUKUYAMA, 20I5).

A ideia de que grandes empresas passariam a dominar o sistema internacional, provocando o enfraquecimento dos Estados nacionais, também foi adotada por vários autores do campo marxista. Entre esses podemos citar Robinson (2007; 2008; 20I4), Harris (20I2), Sklair (2005; 20I7), Sklair e Struna (20I3), Patnaik (20I4) e Petrucciani (20I6). Nessa perspectiva, Marx teria analisado o sistema capitalista quando ainda havia uma base nacional para o capital e o trabalho e as relações internacionais tinham como alicerce as mercadorias produzidas em cada país. Atualmente não existiria mais o "made in USA", mas sim o "made in world" (HARRIS, 20I2). Essa reorganização do capital teria criado algo novo no capitalismo.

De acordo com Robinson (2007; 2008) e Harris (2012), o capitalismo sofreu grandes mudanças desde o período clássico do imperialismo analisado por Hilferding, Lênin e Bukharin, e se encontraria em um novo estágio conhecido como globalização. Segundo esses autores, a globalização seria um produto do capital transnacional, apátrida e disposto à exploração do trabalho em qualquer canto do mundo que lhe proporcione as melhores condições de obter lucro. Na globalização, as economias nacionais seriam um mito.

Assim, atualmente, a dinâmica do sistema capitalista não poderia ser compreendida tendo o Estado-nação como centro. Por isso, o termo globalização — "o último estágio do capitalismo" - seria muito coerente com o momento atual (ROBINSON, 2002; HARRIS, 2012). Harris (2012) afirma que a lógica fundamental do capitalismo não mudou em relação ao seu poder de acumulação e exploração de trabalho. Todavia, os métodos pelos quais ela se realiza na globalização seriam novos. A organização das relações de produção já não estaria baseada nas fronteiras nacionais, mas na força de trabalho global, e nos investimentos e ativos em escala mundial, redefinindo a característica da classe capitalista. As empresas seriam obrigadas a adotar estratégias nessa direção. Isso se revelaria na natureza da concorrência monopolista, que emergiu das rivalidades entre Estados-nações para monopolizar a concorrência entre as corporações transnacionais.

2 "O termo globalização não serve apenas como descrição e explicação do que está acontecendo. Referese ainda mais a uma prescrição — de que certos desenvolvimentos, particularmente 'a liberalização dos mercados nacionais e globais', produzirão 'o melhor resultado para o crescimento e o bem-estar humano' e são do interesse de todos" (PETRAS; VELTMEYER, 2007, p. 39, tradução nossa). 
Robinson $(2007$; 2008) pressupõe pelo menos quatro mudanças fundamentais que marcaram o sistema capitalista nos dias de hoje: I) a ascensão de um capital verdadeiramente transnacional e a integração de todos os países em um novo sistema produtivo e financeiro global. Ainda haveria o capital nacional ou regional, porém o capital transnacional, divorciado de qualquer país, seria então dominante; 2) o aparecimento de uma nova classe capitalista transnacional; 3) a ascensão de aparatos estatais transnacionais, como Fundo Monetário Internacional (FMI), a Organização Mundial do Comércio (OMC) e o Grupo dos Sete $\left(\mathrm{G}_{7}\right)$, entre outros, resultando no que ele chama de "Estado transnacional"; e 4) o aparecimento de novas relações de poder e desigualdade na sociedade global.

A ideia de Estado transnacional poderia sugerir a formação de um concerto entre as principais nações para que a reprodução do capital ocorresse de maneira pacífica em todo o mundo, sem a necessidade de guerras (ultraimperialismo), como acreditava Kautsky (2004). Entretanto, Robinson (2007) sustenta que a sua teoria pouco ou nada compartilha da tese kautskiana do ultraimperialismo, já que esta assume que o capital permaneceria nacional enquanto se uniria internacionalmente. Na sua interpretação, o conflito entre capitais seria endêmico ao sistema, porém, na globalização, ele se apresentaria sob novas formas, não como guerras entre os Estados. Na realidade já não existiriam empresas nacionais, mas sim conglomerados transnacionais a serviço do capitalismo global. Deve-se frisar, na globalização a competição ocorreria entre as grandes corporações, não mais entre os Estados. "Como os Estados nacionais são capturados por forças capitalistas transnacionais, eles tendem a servir aos interesses dos processos de acumulação globais sobre os processos locais" (ROBINSON, 2007, p. I7, tradução nossa).

Segundo Robinson (2008; 2007), o Estado norte-americano seria um instrumento chave para a reprodução e consolidação de um sistema capitalista global, que atuaria em defesa dos interesses de uma burguesia transnacional. Sua burguesia teria sido a primeira a se tornar transnacional’ . Desse modo, "a continuação da existência do Estado nacional é uma condição central não para a 'hegemonia dos EUA' ou para um 'novo império dos EUA', mas para o poder de classe do capital transnacional" (ROBINSON, 2OI4, p. I2I, tradução nossa). Ao contrário dos primeiros momentos do capitalismo mundial, quando foram criadas zonas exclusivas de exploração, como na Índia, pelos ingleses, e na Indonésia, pela Holanda, na globalização as conquistas permitiriam a exploração global (ROBINSON, 2007, p. 20). Podemos dizer então que para esses autores estaríamos praticamente diante de uma nova "Santa Aliança" das forças transnacionais, a fim de manter o mundo estável para a exploração das grandes empresas.

Assim, o aumento da militarização dos Estados Unidos após o II de Setembro não estaria relacionado com uma busca pela hegemonia, nem com o ressurgimento das rivalidades interimperialistas. A militarização seria uma resposta contraditória à crise profunda do capitalismo global iniciada no fim da década de I990. Essa crise

3 Sunkel e Fuenzalida (1979) já expressavam essa mesma opinião. Cf. também Michalet (1983). 
envolveria três dimensões inter-relacionadas: I) crise de polarização social: o sistema não conseguiria atender às necessidades da maior parte da humanidade, isto é, a sua reprodução social básica; 2) crise estrutural de superacumulação: a polarização social em todo o mundo provocada pela globalização teria restringido a capacidade do mercado mundial em absorver a produção, reduzindo a capacidade de expansão do sistema. A invasão do Iraque, por exemplo, teria criado condições favoráveis para a penetração do capital transnacional e ajudado a integrar a região ao capitalismo global, ajudando a solucionar o problema da insuficiência de demanda (subconsumo); e 3) crise de legitimidade e autoridade: os conflitos entre Estados deveriam ser vistos como conflito entre forças sociais transnacionais (burguesia "global", proletariado "global"), que operariam por meio de Estados e outras instituições. Isso teria levado a que milhões de pessoas em todo o mundo passassem a questionar a legitimidade do sistema (ROBINSON, 2007).

Ao não observarem essas três dimensões inter-relacionadas, as teorias do novo imperialismo falhariam por permanecer vinculadas às ideias da existência de rivalidade entre economias nacionais, de conflito entre potências capitalistas centrais e da exploração por essas potências de economias periféricas. Essas são características do capitalismo da primeira metade do século XX que não existiriam na globalização (ROBINSON, 20I4). Agora, os Estados nacionais promoveriam os interesses do capital global em detrimento das elites locais.

A ideia de classe capitalista transnacional é mais bem desenvolvida por Sklair (2005). Segundo Sklair, essa seria uma classe de pessoas de muitos países que operam de forma transnacional como parte de suas vidas profissionais, e que na maioria das vezes têm mais de um lugar que consideram sua residência. A criação de transportes velozes e confortáveis de longa distância e de meios de comunicação eletrônica teria tornado isso possível como em nenhum outro momento da história. Daí que o conceito de globalização seria o mais apropriado para descrever as condições econômicas, políticas e culturais que prevalecem atualmente. Sklair e Struna (2013) e Sklair (2005) dividem a classe capitalista transnacional em quatro frações: I) executivos de corporações (fração corporativa); 2) políticos globalizados e burocratas (fração estatal); 3) profissionais globalizados (fração técnica); e 4) comerciantes e mídia (fração consumerista). A fração consumerista é a responsável por transmitir o que esses autores chamam de ideologia consumerista, um conjunto de práticas que levam a sociedade a consumir além de suas necessidades (capitalismo consumerista). Os shoppings centers, os parques temáticos e marcas como Hermès, Ducati, Jeep e Mazda seriam ícones ou objetos da ideologia consumerista (SKLAIR; STRUNA, 2013; SKLAIR, 20I7).

Aqueles que lideram a classe capitalista transnacional teriam a missão de organizar as condições sob as quais seus interesses e os interesses do sistema capitalista podem ser promovidos no contexto global e local (SKLAIR; STRUNA, 20I3; SKLAIR, 2005). "O conceito implica a existência de uma classe capitalista central que toma decisões em todo o sistema e cujos membros também se conectam com a fração da classe capitalista transna- 
O conceito de imperialismo não se tornou obsoleto, porém sofreu mudanças importantes na era da globalização. Atualmente a grande burguesia no então chamado Terceiro Mundo sofreu uma mudança que deveria ser destacada: ela estaria rigorosamente integrada na "globalização do capital", disputando mercados como qualquer "ator global" do mundo desenvolvido cional" (SKLAIR, 2005, p. 486, tradução nossa). As quatro frações abordadas seriam categorias analíticas distintas, cada uma com sua função no sistema capitalista global. Porém, as pessoas frequentemente $\mathrm{mu}$ dam de uma categoria para outra. Sklair (2005) cita o caso comum dessa mobilidade, que ocorre entre negócios e governo e vice-versa, funcionando como "porta giratória" no sistema. Aqui também não existe espaço para discutir imperialismo.

Patnaik (20I4) argumenta que o conceito de imperialismo não se tornou obsoleto, porém sofreu mudanças importantes na era da globalização. Atualmente a grande burguesia no então chamado Terceiro Mundo sofreu uma mudança que deveria ser destacada: ela estaria rigorosamente integrada na "globalização do capital", disputando mercados como qualquer "ator global" do mundo desenvolvido. Nos passos de Rosa Luxemburgo, Patnaik (2014) concebe o imperialismo como a exploração, pelas potências capitalistas, da população trabalhadora dos países ainda não predominantemente capitalistas. E essa situação permanece na globalização, ainda que com diferenças importantes. Atualmente, a exploração de pequenos produtores pré-capitalistas no Terceiro Mundo - que fornecem mercadorias com preços baixos - tem o objetivo de manter o valor do dinheiro estável, preocupação central do capitalismo na era da financeirização.

Embora rejeite a noção de conflito entre economias centrais e periféricas, a teoria do capital transnacional tem em comum com a noção de imperialismo de Luxemburgo, Baran e Sweezy e com a teoria da dependência a ideia de subconsumo dos trabalhadores. Nesse caso, o imperialismo seria resultado de uma crise (superprodução de mercadorias) do capitalismo, que a busca por mercados externos para lançar a produção excedente poderia resolver.

No entanto, essa é uma visão problemática no pensamento marxista. Primeiro, porque reduz o imperialismo a um problema de crise econômica. Segundo, porque afirmar que o capitalismo tem um problema de falta de consumo das massas equivale 


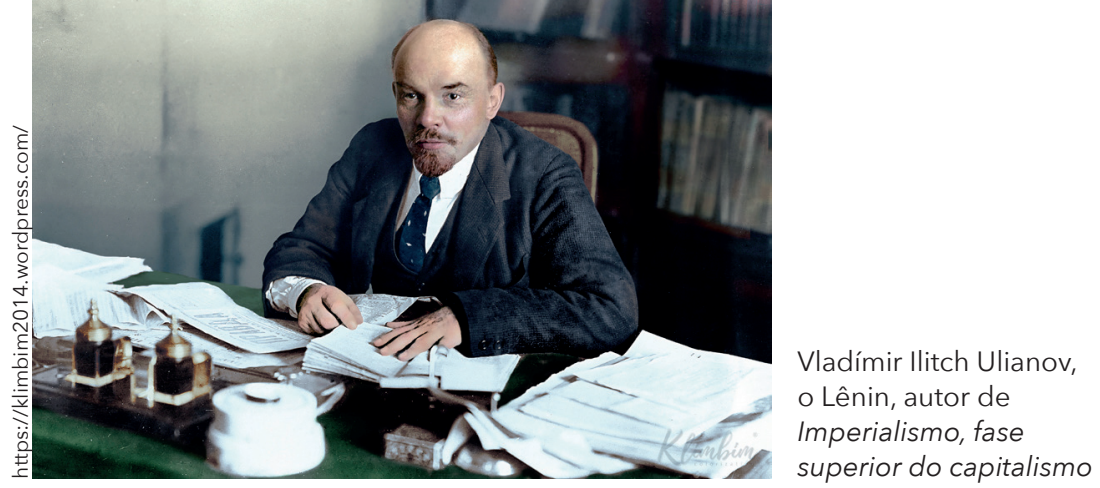

a afirmar que o capitalismo produz para as massas (MAZZUCCHELLI, 1985). Na realidade, segundo Marx (2013), no modo de produção capitalista a riqueza produzida não serve às necessidades do trabalhador, mas o trabalhador serve às necessidades de valorização do capital. Ora, se o consumo dos trabalhadores fosse um problema crucial, o capitalismo estaria estagnado há décadas, pois uma das peculiaridades do capitalismo é que ele se sustenta justamente na ampliação da produção de forma desmedida. A produção pela produção. Voltaremos a esse ponto mais à frente.

\section{IMPERIALISMO E DESENVOLVIMENTO DESIGUAL}

O conceito de globalização tem sido criticado por diversos autores. Por exemplo, Halliday (2002); Harman (20I0); Petras e Veltmeyer (2007); Ruccio (2003); Milios; Sotiropoulos (20I4); e Sakellaropoulos (2009; 20I8). De acordo com Sakellaropoulos (2009), a ideia de globalização suprime uma série de questões relacionadas ao desenvolvimento histórico das relações de exploração no sistema capitalista e ao papel do imperialismo como referência teórica e histórica. O imperialismo é o resultado das tendências inerentes ao processo de acumulação de capital e às contradições que surgem da luta de classes no capitalismo. A sua principal característica é justamente a internacionalização do capital em decorrência da concentração e centralização do capital, não a ocupação de territórios como ocorria na era colonial ${ }^{4}$. Esta é uma característica das formações pré-capitalistas, em parte analisada por Marx no capítulo XXIV - "A assim chamada acumulação primitiva" - de O Capital. Agora, a dominação acontece fundamentalmente por meio dos imperativos econômicos, como assinalou Wood (2003) , embora ocupações territoriais ainda possam ocorrer, como no caso das guerras do Afeganistão (200I) e do Iraque (2003-20II).

O sistema internacional é composto majoritariamente por Estados capitalistas cujo objetivo é reproduzir o poder de suas próprias burguesias, buscando melhorar suas posições na competição econômica. A ideia de "burguesia nacional" realmente pode não ser a mais adequada, na medida em que os empresários estão muito

4 "Para Lênin, em particular, o imperialismo não se referia especificamente à posse de colônias. Ele reconheceu explicitamente que as fases anteriores do capitalismo também envolviam a expansão colonial, mas por diferentes razões e com resultados diferentes." (BREWER, 1990, p. 123, tradução nossa)

5 Entretanto, Wood (2003) tem dificuldade de entender que nem sempre os Estados utilizam os imperativos econômicos como coerção. Ainda que não incorporem territórios formalmente, os Estados Unidos, por exemplo, permanecem atuando para desestabilizar governos, inclusive com intervenções militares diretos. 


\section{Os Estados utilizam as estruturas de poder desigual a fim de manter e conquistar espaços de acumulação, segundo os interesses dos seus capitalistas. No sistema atual as multinacionais continuam precisando do seu Estado de origem, ainda que novas formas de atuação tenham surgido com o desenvolvimento do capitalismo. Em momentos em que se acirra a competição, o uso do poder por parte dos Estados é sempre bem-vindo}

mais preocupados com a taxa de lucro dos seus investimentos, independentemente de onde estes estão localizados, do que com ideias abstratas como o amor à pátria. No entanto, a grande empresa continua tendo um Estado nacional, fornecendo proteção e apoio para enfrentar a concorrência internacional (GONÇALVES, 2005; SAKELLAROPOULOS, 20I8).

E, ao contrário daqueles que advogam a existência de um "Estado transnacional", os organismos multilaterais como a OMC e seu mecanismo de solução de controvérsias são uma forte evidência de como os Estados atuam visando atender primeiramente a suas respectivas burguesias. Isso evidentemente não contradiz o fato de que essas organizações estão comprometidas com o capitalismo. A força de trabalho também se reproduz dentro de cada Estado, com seu próprio sistema de previdência, de saúde, de educação pública e de concessão seguro-desemprego e outros benefícios que influenciam direta ou indiretamente no custo de reprodução da força de trabalho (SAKELLAROPOULOS, 20I8, p. I2; BRUNHOFF, I985). É sob essas condições que os investimentos das multinacionais são incorporados ao processo de acumulação do país hospedeiro.

Assim, se não existe um capital global nem um proletariado global, não faria sentido falar em globalização (SAKELLAROPOULOS, 2009). O capitalismo se reproduz dentro das formações sociais nacionais ${ }^{6}$, que estão interligadas como parceiros desiguais dentro do sistema. O capitalismo para se reproduzir precisa do Estado-nação. É o Estado que busca garantir os interesses de longo prazo do capital, adminis-

6 Sobre a categoria de formação social, cf. Santos (1982). É importante lembrar que Lênin teve um papel fundamental no desenvolvimento dessa categoria no materialismo histórico. 
trando a gestão política da força de trabalho ${ }^{7}$, intervindo para assegurar os lucros do capital nacional e promovendo sua expansão no espaço internacional ${ }^{8}$.

Por sua vez, a exportação de capitais acirra a competição entre os Estados-nação, pois estes também têm a função de intermediar os interesses de diferentes classes dominantes numa relação complexa e contraditória. Os monopólios podem se associar em diversas partes do mundo, todavia precisam estar estreitamente ligados aos seus Estados nacionais de origem, nos quais recebem proteção legal ou mesmo fora das regras jurídicas, quando for conveniente (HARMAN, 2003). Nessa perspectiva, os conflitos internacionais (econômicos, políticos e/ou militares) são intrínsecos ao sistema, não obstante momentos de cooperação possam predominar.

Os Estados utilizam as estruturas de poder desigual a fim de manter e conquistar espaços de acumulação, segundo os interesses dos seus capitalistas. No sistema atual as multinacionais continuam precisando do seu Estado de origem, ainda que novas formas de atuação tenham surgido com o desenvolvimento do capitalismo. Em momentos em que se acirra a competição, o uso do poder por parte dos Estados é sempre bem-vindo.

Por sua vez, a internacionalização do capital não decorre da falta de consumo ou de algum limite estrutural que leve à estagnação da economia capitalista, como acreditam várias correntes do marxismo, em especial aquelas de que tratamos na segunda seção. Na visão de Lênin, a internacionalização do capital é a expressão da tendência à expansão agressiva do capital em todas as partes do mundo, independentemente do nível de consumo ou da queda da taxa de lucro. Além disso, o processo de internacionalização está envolto em características sobretudo históricas. No período em que prevaleceram os acordos de Bretton Woods (I944-I97I), conhecido como a "era de ouro do capitalismo", a movimentação de capitais de curto prazo ficou restrita em razão dos controles exercidos pelos países. Firmou-se, naquela época, um consenso a respeito da responsabilidade das finanças internacionais no desencadeamento da Grande Depressão, durante o entreguerras. No período de Bretton Woods as taxas de câmbio ficaram estáveis, contribuindo para a expansão do comércio. Após o rompimento da paridade dólar-ouro, em I97I — de forma unilateral, pelo governo norte-americano a desregulamentação dos mercados financeiros entrou novamente na agenda.

\section{I. Cadeia imperialista}

Na análise de Lênin (I979; s.d.) já se encontra uma crítica à noção - comum na esquerda nos anos I9IO e I920 - de "capitalismo global”, segundo a qual o imperialismo era entendido como uma estrutura socioeconômica global uniforme (MILIOS; SOTIROPOULOS, 20I4). Nesse sentido, a chamada cadeia imperialista fornecia uma

7 De acordo com Brunhoff (1985, p. 7): "O primeiro eixo principal da intervenção econômica do Estado é a gestão da força de trabalho como mercadoria particular. Essa gestão responde a uma necessidade do capital, que não pode ser diretamente satisfeita pelo próprio capital."

8 Conforme Poulantzas (1977, p. 32), a luta de classes "se situa sempre, no essencial, no quadro do espaço nacional e se reverte sempre de uma forma nacional por excelência". 
descrição importante das relações hierárquicas desiguais advindas da reprodução do capital no sistema internacional.

A cadeia imperialista ${ }^{9}$ agrega um conjunto de economias capitalistas, cada qual com um nível de desenvolvimento. Isso implica o entrelaçamento das diferentes estruturas econômicas e sociais constituídas, cada uma das quais condicionada pela luta de classes que se materializa dentro do Estado nacional. A internacionalização do capital por meio da exportação de capitais ${ }^{\mathrm{IO}}$ — entendida não somente como investimento em outros países, mas como um meio de expandir as relações sociais do capitalismo - e a criação do mercado internacional, com o surgimento dos grandes monopólios, uniram as diferentes formações sociais capitalistas e produziram conexões complexas e instáveis. Ao mesmo tempo, em seu duplo movimento, o imperialismo forma novas estruturas e subverte antigas (HALLIDAY, 2007), provocando mudanças na política e na ideologia em escala internacional (POULANTZAS, 1979).

Portanto, o processo de internacionalização do capital é um problema relacionado com as condições concretas do desenvolvimento do capitalismo nas diversas nações e em diferentes épocas. Vale destacar, é o próprio desenvolvimento desigual dos ramos industriais, a generalização da produção mercantil e a sua agressiva progressividade que impulsionam o capitalismo em busca de mercados externos.

Além disso, a noção de cadeia imperialista conduziria à formulação de duas questões intrinsecamente ligadas: a lei do desenvolvimento desigual e a noção do "elo mais fraco" (MILIOS; SOTIROPOULOS, 20I4). Em razão do próprio movimento do capital, os países se desenvolvem em ritmos diferentes. Na visão de Lênin, ao contrário do que se convencionou entender com base na teoria da dependência, existe a tendência estrutural de que os países mais desenvolvidos tenham uma taxa de crescimento econômico menor em relação aos países menos desenvolvidos, no próprio centro capitalista ou na periferia do sistema (FERNANDES, 20I6). Assim, ainda segundo Lênin, a estabilidade do sistema é impossível ${ }^{\text {II }}$, pois o desenvolvimento desigual provocaria mudanças na correlação de forças das nações mais avançadas. Como consequência, as contradições entre as potências que compõem a cadeia imperialista se intensificariam. Esse é o resultado necessário da complexa emergência e dominação do capitalismo em diferentes partes do mundo (LÊNIN, (I979; s.d.).

A lei do desenvolvimento desigual é decisiva para explicar as relações entre os países da cadeia imperialista, oferecendo uma base econômica para os conflitos militares. O desenvolvimento desigual também cria a possibilidade de revoluções nos elos relativamente mais fracos da cadeia, e não naqueles Estados em que as forças

9 A formulação do conceito de cadeia imperialista não se encontra de maneira explícita nos principais textos de Lênin sobre o imperialismo. Mas foi desenvolvido por outros autores, entre eles Nicos Poulantzas.

10 Vale lembrar que a exportação de capitais é um traço fundamental do imperialismo. "O que caracterizava o antigo capitalismo, no qual dominava a livre concorrência, era a exportação de mercadorias. $\mathrm{O}$ que caracteriza o capitalismo moderno, em que impera o monopólio, é a exportação de capital." (LÊNIN, 1979, p. 730, tradução nossa)

11 Ainda que em determinados momentos possam ocorrer acordos temporários entre capitalistas e Estados (LÊNIN, 1974). 


\section{A instabilidade econômica e política resultante da crise financeira de 2008 é um dos exemplos mais reveladores quanto à incapacidade das grandes potências em criar um acordo que limite os efeitos deletérios dos mercados financeiros desregulados}

produtivas estariam mais avançadas, ao contrário do que Marx inicialmente pensava. É importante destacar que essa é uma posição relativa: os países que fazem parte da cadeia imperialista são mais fracos ou mais fortes em relação aos demais elos da cadeia (POULANTZAS, 1979, p. 23).

\subsection{Obstáculos à "governança econômica global"?}

Por meio do conceito de imperialismo desenvolvido por Lênin podemos discutir a chamada "governança econômica global". As instituições multilaterais alcançaram importância significativa nas últimas décadas, sendo consideradas atores importantes no sistema internacional. Entretanto, instituições como o FMI e o Banco Mundial estão a serviço das grandes potências, que não raro apresentam interesses divergentes, como demonstra a dificuldade em realizar qualquer reforma nessas duas instituições.

Portanto, a construção da chamada "governança econômica global" é uma tarefa praticamente inalcançável. Durante os anos 1990, quando os Estados Unidos mantiveram uma expansão econômica excepcional, foi possível manter sua hegemonia sobre as demais potências, impedindo com relativo sucesso estratégias regionais autônomas. Isso não eliminou as contradições do país nem o tornou menos belicoso (FIORI, 2008; SAKELLAROPOULOS; SOTIRIS, 2015). Ocorre que, com o fim da Guerra Fria, alguns meios de intervenção passaram a ser considerados legítimos pelas potências centrais, com base em justificativas como a repressão às violações de direitos humanos, o ataque aos cartéis de drogas na América Latina, o combate à corrupção, a manutenção da segurança internacional e, mais recentemente, a guerra preventiva contra o terrorismo ${ }^{\mathrm{I} 2}$ (BANDEIRA, 20I4; JOHNSON, 2004).

12 Conforme Fiori (2014, p. 209), "tudo indica que neste novo universo ampliado e sem a ameaça comunista, as grandes potências ocidentais decidiram transformar a questão do 'respeito aos direitos humanos' no novo grande princípio ético legitimador das suas velhas 'guerras civilizatórias'". 
Todavia, o balanço de forças entre diferentes Estados está em constante mudança. À medida que a lei do desenvolvimento desigual se impõe, novos polos de poder vão surgindo. A cooperação se torna mais problemática com a crescente multipolarização do sistema internacional - como pode ser observado pela formação dos Brics, por exemplo - e, consequentemente, com a decomposição relativa do poder dos Estados Unidos, a que se assiste atualmente. Nesses termos é possível entender a reação crescente à política externa norte-americana, que após o II de Setembro passou a utilizar uma linguagem claramente belicista e intervencionista. Desde então os Estados Unidos têm fomentado conflitos em diversos territórios em todo o mundo, ignorando a soberania de países como o Afeganistão (200I) e o Iraque (2003-20II).

A instabilidade econômica e política resultante da crise financeira de 2008 é um dos exemplos mais reveladores quanto à incapacidade das grandes potências em criar um acordo que limite os efeitos deletérios dos mercados financeiros desregulados. Ainda em 2009, líderes do Grupo dos 20 (G20) se comprometeram a realizar o que fosse necessário para restaurar a confiança na economia mundial. Os fundos de hedge, os paraísos fiscais e as agências de classificação de risco entraram na mira da regulação que deveria acontecer. No entanto, passados os piores momentos da crise, a recuperação econômica permanecia frágil, e as principais potências capitalistas buscaram atender a seus próprios interesses, mesmo que a expensas de outras economias, como foi com a política do quantitative easing, levada a cabo pelo FED, banco central dos Estados Unidos. Caminho semelhante trilhou a Alemanha na crise europeia que se seguiu à crise financeira de 2008, quando impôs medidas draconianas de ajustamento aos países que estavam em pior situação, como Portugal e Grécia (BLYTH, 20I7).

Mesmo agora que o mundo assiste, por conta da pandemia de covid-I9, a uma crise sanitária de proporções ainda não totalmente claras, não se consegue alcançar um plano mundial que unifique os governos em torno de uma saída comum e que impeça a propagação do vírus ou que reduza os efeitos negativos da pandemia na atividade econômica. Pelo contrário, cada país vem buscando suas próprias soluções. Por exemplo, no primeiro semestre de 2020, quando a Europa e depois os Estados Unidos se tornaram o epicentro da crise sanitária, ocorreu uma guerra pela apropriação de máscaras N95 e respiradores, além de ataques do governo norte-americano à Organização Mundial da Saúde (OMS), justamente a principal organização multilateral na área da saúde ${ }^{13}$.

E quando se iniciou a produção das vacinas, a assimetria de poder entre os países se destacou novamente. No fim de 2020, o grupo People’s Vaccine Alliance, que reúne organizações como a Oxfam e a Anistia Internacional, denunciou os países ricos por estarem reservando para suas populações mais doses da vacina contra a covid-I9 do que realmente precisavam, o que deixaria desamparada a população de países subdesenvolvidos (RICH..., 2020).

13 Os ataques à OMS se deram por conta de uma suposta conivência da organização com a China, que, segundo o então presidente Donald Trump insinuava, teria espalhado propositalmente o coronavírus pelo mundo. 


\section{CONSIDERACÕ̃ES FINAIS}

Neste trabalho buscou-se mostrar a atualidade do conceito de imperialismo para o entendimento das relações entre os Estados. Como vimos, no fim do século XX, mesmo autores da tradição marxista passaram a usar o termo globalização como forma de explicação do momento atual, por entenderem que a ideia de imperialismo já não seria mais adequada. Autores como Robinson e Sinklair acreditam que o capital já não se vincula aos seus Estados nacionais. Estaríamos na era das empresas transnacionais, em que a principal potência, os Estados Unidos, utilizaria seu poder para a reprodução do sistema capitalista global, atuando como defensora dos interesses do grande capital em qualquer parte do mundo.

Por nossa vez, entendemos que a teoria leninista do imperialismo consegue compreender o sistema internacional de forma mais satisfatória. Conforme observamos, a análise de Lênin sobre o imperialismo não se limita a um olhar estritamente econômico ou político. A ideia de cadeia imperialista ainda é uma maneira de compreender as relações entre as economias capitalistas em distintos níveis de desenvolvimento e de estruturas econômicas e sociais constituídas. Em Lênin observamos que o capitalismo não pode funcionar sem o Estado. Como não existe um governo global, o capital não pode se expandir para além das fronteiras nacionais sem o Estado.

De tal modo, sugerimos que a atual conjuntura está mais próxima da perspectiva de Lênin do que do prisma daqueles que estão vinculados à noção de "globalização". Observa-se um crescimento da instabilidade econômica e política em várias partes do mundo. Os reflexos da crise de 2008 ainda repercutem, e as reformas aventadas como importantes para uma nova governança econômica global não avançam. Assim sendo, em um momento em que se acirram as contradições do capitalismo, o conceito de imperialismo permanece como um indispensável instrumento para a reflexão política.

\footnotetext{
* Professor associado Il, vice-coordenador do curso de Ciências Econômicas e docente do Programa de Pós-Graduação em Economia Regional e Desenvolvimento (PPGER) da Universidade Federal Rural do Rio de Janeiro (UFRRJ). Doutor em Economia pela Universidade Federal Fluminense (UFF). Membro do Conselho Federal de Economia (Cofecon) e do Conselho Regional de Economia do Rio de Janeiro (Corecon-RJ). Membro do grupo de pesquisa Padrões Históricos do Desenvolvimento Econômico da América do Sul e do Laboratório Interdisciplinar de Estudos em Relações Internacionais. Tem interesse nas áreas de economia política, economia política internacional, imperialismo e história econômica geral, economias da América do Sul e economias dos Brics.
}

Texto recebido em fevereiro de 2021; aprovado em fevereiro de 2021 
BANDEIRA, Luiz Alberto Moniz. A segunda Guerra Fria: geopolítica e dimensão estratégica dos Estados Unidos - das rebeliões na Eurásia à África do Norte ao Oriente Médio. 2. ed. Rio de Janeiro: Civilização Brasileira, 2014.

BARAN, Paul; SWEEZY, Paul. Capitalismo monopolista: ensaio sobre a ordem econômica e social americana. Rio de Janeiro: Zahar, 1978.

BLYTH, Mark. Austeridade: a história de uma ideia perigosa. São Paulo: Autonomia Literária, 2017.

BREWER, Anthony. Marxist Theories of Imperialism: a critical survey. 2. edition. London and New York: Routledge, 1990.

BRUNHOFF, Suzanne de. Estado e capital: uma análise da política econômica. Rio de Janeiro: Forense-Universitária, 1985.

CAMMACK, Paul. Forget the transnational state. Papers in the Politics of Global Competitiveness, n. 3, 2007. Disponível em: <https://ssrn.com/abstract=1526528>. Acesso em: 10 dez. 2020.

FERNANDES, Luis. Transição global e ruptura institucional: a geopolítica do neologismo no Brasil e na América Latina. Princípios, São Paulo, n. 143, p. 30-40, 2016.

FIORI, José Luís. Geopolítica e ética internacional. In:

. História, estratégia e desenvolvimento: para uma geopolítica do capitalismo. São Paulo: Boitempo, 2014.p.208-210.

O sistema interestatal capitalista no início do século XXI. In: MEDEIROS, Carlos; SER-

RANO, Franklin. O mito do colapso do poder americano. Rio de Janeiro: Record, 2008. p.11-70.

FRANK, Andre Gunder. Capitalism and underdevelopment in Latin America. New York: Monthly Review Press, 1967.

FRANKEL, Jeffrey A. Globalization of the economy. NBER, working paper 7858, 2000. Disponível em: <www.nber.org/papers/w7858>. Acesso em: 27 fev. 2021.

FUKUYAMA, Francis. O fim da história e o último homem. São Paulo: Rocco, 2015.

GONÇALVES, Reinaldo. Economia política internacional: fundamentos teóricos e as relações internacionais do Brasil. Rio de Janeiro: Elsevier, 2005

HALLIDAY, Fred. Repensando as relações internacionais. 2. ed. Porto Alegre: Editora da UFRGS, 2007.

The pertinence of imperialism. In: RUPERT, Mark; SMITH, Hazel (Ed.). Historical materialism and globalization. London: Routledge, 2002.p.210-229.

HARMAN, Chris. Analysing imperialism. Marxists Internet Archive, 2003. Disponível em: <www. marxists.org/archive/harman/2003/xx/imperialism.htm>. Acesso em: 27 fev. 2021.

Zombie capitalism: global crisis and the relevance of Marx. Chicago: Haymarket Books, 2010.

HARRIS, Jerry. Global monopolies and the transnational capitalist class. International Critical Thought, v. 2, n. 1, p. 1-6, 2012.

DI GIOVANNI, Julian et al. Globalization: a brief overview. IMF, 2008. Disponível em: <www.imf.org/ external/np/exr/ib/2008/053008.htm>. Acesso em: 27 fev. 2021.

KAUTSKY, Karl. Ultra-imperialism. Marxists Internet Archive, 2004. Disponível em: <www.marxists. org/archive/kautsky/1914/09/ultra-imp.htm>. Acesso em: 12 jan. 2021.

LÊNIN, Vladimir llitch. El imperialismo, fase superior del capitalismo. In: Obras escogidas. Moscou: Editorial Progreso, 1979. t. 1, p.677-787.

Imperialism and the split in socialism, Marxists Internet Archive, [s.d.]. Disponível em:<www. marxists.org/archive/Lênin/works/1916/oct/x01.htm>. Acesso em: 27 fev. 2021.

On the slogan for a United States of Europe. In: Collected works. Moscow: Progress Publishers, 1974. v. 21, p. 339-343.

LUXEMBURGO, Rosa. A acumulação do capital: estudo sobre a interpretação econômica do imperia- 
lismo. Tradução Luiz Alberto Moniz Bandeira. Rio de Janeiro: Zahar, 1970.

MARINI, Ruy Mauro. A acumulação capitalista mundial e o subimperialismo. Outubro, n. 20, jan.-jun. 2012. Disponível em: <http://outubrorevista.com.br/wp-content/uploads/2015/02/Revista-Outubro-Edic\%CC\%A7a\%CC\%83o-20-Artigo-02.pdf>. Acesso em: 27 fev. 2021.

Subdesarrollo y revolución. México: Siglo XXI, 1980.

MARQUES, Rosa Maria. Globalização e Estados nacionais. Crítica Marxista, São Paulo, v. 1, n. 3, p. 136-139, 1996.

MARX, Karl. O Capital: crítica da economia política. Livro III - O processo global da produção capitalista. São Paulo: Boitempo, 2017.

MAZZUCCHELLI, Frederico. A contradição em processo: o capitalismo e suas crises. São Paulo: Brasiliense, 1985.

MICHALET, Charles-Albert. O capitalismo mundial. Rio de Janeiro: Paz e Terra, 1983.

MILIOS, John; SOTIROPOULOS Dimitris P. Rethinking imperialism: a study of capitalist rule. Houndmills: Palgrave Macmillan, 2009.

Revisiting the classical theories of imperialism: from underconsumption in global capitalism to the imperialist chain. Spectrum Journal of Global Studies, v. 6, n. 1, 2014.

MORAES, João Quartim de. A miragem global e a rearticulação imperialista. Crítica Marxista, São Paulo, v. 1, n. 3, p. 143-145, 1996.

PATNAIK, Prabhat. Has imperialism become an obsolete concept? In: BAGCHI, Amiya Kumar; CHATTERJEE, Amita. Marxism with and beyond Marx. London; New York: Routledge, 2014.

PETRAS, James; VELTMEYER, Henry. Globalisation or imperialism?. Cambridge Review of International Affairs, v. 14, n. 1, 2007.

PETRUCCIANI, Stefano. Le concept de classe dominante dans la théorie politique marxiste. Actuel Marx, n. 60, p. 12-27. 2016.

POULANTZAS, Nicos. As transformações atuais do Estado, a crise política e a crise do Estado. In: O Estado em crise. Rio de Janeiro: Graal, 1977.p.3-41.

1979.

Fascism and dictatorship: The Third International and the problem of fascism. London: Verso,

RICH countries hoarding covid vaccines, says People's Vaccine Alliance. BBC News, 9 december 2020. Disponível em: <www.bbc.com/news/health-55229894>. Acesso em: 10 jan. 2021.

ROBINSON, William. Beyond the theory of imperialism: global capitalism and the transnational state. Societies Without Borders, v. 2, n. 1, p. 5-26, jan. 2007.

Capitalist globalization and the transnationalization of the state. In: RUPERT, Mark; SMITH, Hazel (Ed.). Historical materialism and globalization. London: Routledge, 2002., p.210-229

Global capitalism and the crisis of humanity. New York: Cambridge University Press, 2014.

Understanding global capitalism. The Development Roundtable Series, jan. 2008. Disponível em: <www.soc.ucsb.edu/faculty/robinson/Assets/pdf/understandingglobalcapitalism.pdf>. Acesso em: 27 fev. 2021.

RUCCIO, David. Globalization and imperialism. Rethinking Marxism, v. 15, n. 1. p. 75-94, 2003.

Reading Gramsci in an era of globalising capitalism. Critical Review of International Social and Political Philosophy, v. 8, n. 4, p. 483-497, dez. 2005.

SANTOS, Milton. Espaço e sociedade: ensaios. 2. ed. Petrópolis: Vozes, 1982. 
SANTOS, Theotônio dos. Imperialismo e dependência na América Latina. In: BONILLA, Frank; GIRLING, Robert (Ed.). Structures of dependency. Palo Alto: Stanford-Institute of Political Studies, 1973.

SAKELLAROPOULOS, Spyros. The issue of globalization through the theory of imperialism and the periodization of modes of production. Critical Sociology, v. 35, n. 1, p. 57-78, 2009.

The theoretical weakness of theses positing emergence of a transnational bourgeoisie and a transnational state: a critique of the views of William Robinson. Journal of Labor and Society, v. 21, n. 4 , p. 579-596, 15 dez. 2018.

; SOTIRIS, Panagiotis. From territorial to nonterritorial capitalist imperialism: Lênin and the possibility of a Marxist theory of imperialism. Rethinking Marxism, v. 27, n. 1, p. 85-106, 2015.

SCOTT, Bruce. The great divide in global village. Foreign Affairs, v. 80, n. 1, jan.-fev. 2001.

SKLAIR, Leslie. The icon project: architecture, cities, and capitalist globalization. New York: Oxford University Press, 2017.

The transnational capitalist class and contemporary architecture. International Journal of Urban and Regional Research, v. 29, n. 3, set. 2005.

; STRUNA, Jason. The icon project: the transnational capitalist class in action, Globalizations, v. 10, n. 5, p. $747-763,2013$.

SUNKEL, Osvaldo; FUENZALIDA, Edmundo F. Globalizing cities, transnationalization and its national consequences. In: VILLAMIL, José J. (Ed.). Transnational capitalism and national development: new perspectives on dependence. Brighton: Harvester Press, 1979.

TASSO, Paulo. Globalização ou imperialismo. Crítica Marxista, São Paulo, v. 1, n. 3, p. 146-149, 1996.

WALLERSTEIN, Immanuel. The capitalist world-economy. Cambridge: Cambridge University Press, 1979.

WOOD, Ellen Meiksins. Empire of capital. London: Verso, 2003. 